\title{
Enhanced nucleation density by heat treatment of nanodiamond seed particles
}

\author{
Jong Cheon Park, Ok Geun Jeong, Bit Na Son* and Hyun Cho*, \\ Department of Nano Fusion Technology, Pusan National University, Miryang 627-706, Korea \\ *Department of Nanomechatronics Engineering, Pusan National University, Miryang 627-706, Korea
}

(Received October 11, 2013)

(Revised November 12, 2013)

(Accepted November 15, 2013)

\begin{abstract}
Surface chemical modification via air and hydrogen heat treatment was found to relieve the aggregation of nanodiamond (ND) seed particles and lead to a significantly enhanced nucleation density for ultrananocrystalline diamond (UNCD) film growth. After heat treatment in air and hydrogen, modification of surface functionalities and increase in the zeta potential were observed. Mean size of the ND aggregates was also dramatically reduced from $\sim 2 \mu \mathrm{m}$ to $\sim 55 \mathrm{~nm}$. Si surface seeded with ND particles heat-treated at $600^{\circ} \mathrm{C}$ in hydrogen produced a much higher nucleation density of $\sim 2.7 \times 10^{11} \mathrm{~cm}^{-2}$ compared to untreated ND seeds.
\end{abstract}

Key words Nanocrystalline diamond seeds, Aggregation, Heat treatment, Surface chemical modification, Nucleation density

\section{나노다이아몬드 seed 입자의 열처리에 의한 핵형성 밀도 향상}

박종천, 정옥근, 손빛나*, 조현*;

부산대학교 나노융합기술학과, 밀양, 627-706

*부산대학교 나노메카트로닉스공학과, 밀양, 627-706

(2013년 10월 11일 접수)

(2013년 11월 12일 심사완료)

(2013년 11월 15일 게재확정)

요 약 산화 및 수소 분위기 열처리를 통한 화학적 표면 개질로 나노다이아몬드 seed 입자의 응집성 완화 및 초미세나 노결정질 다이아몬드 (UNCD) 박막 증착을 위한 핵형성 밀도 향상을 확보하였다. 열처리에 의해 나노다이아몬드 seed 입자 표면 작용기가 개질되었고, 제타 전위도 증가하였다. 또한, 응집체 평균 크기가 약 $2 \mu \mathrm{m}$ 에서 $~ 55 \mathrm{~nm}$ 로 크게 감소하였다. $600^{\circ} \mathrm{C}$, 수소 열처리된 seed 입자로 seeding 한 $\mathrm{Si}$ 기판으로부터 열처리하지 않은 seed 입자에 비해 현저하게 향상된 $2.7 \times 10^{11} \mathrm{~cm}^{-2}$ 의 매우 높은 핵형성 밀도를 확보하였다.

\section{1. 서 론}

초미세나노결정질 다이아몬드(ultrananocrystalline diamond, UNCD) 박막은 나노미터 스케일의 매우 작은 크 기의 입자로 구성된 미세구조를 가진 다이아몬드 박막을 말한다. UNCD 박막은 마이크로미터 크기의 각진 입자 (faceted grain) 형상을 가지는 마이크로결정질 다이아몬 드(microcrystalline diamond, $\mathrm{MCD}$ )와 달리 매우 평탄 한 표면특성을 가질 뿐만 아니라 마이크로결정질 다이아 몬드 박막에 비해 더 낮은 온도에서 증착이 가능하기 때

\footnotetext{
Corresponding author

Tel: +82-55-350-5286

Fax: +82-55-350-5289

E-mail: hyuncho@pusan.ac.kr
}

문에 매우 얇은 박막의 형태로부터 천연 다이아몬드의 고유한 특성을 구현하는 것이 가능하다. 또한, 우수한 기 계적, 화학적, 전기적 특성을 가져 초저마모 보호코팅, 전기화학적 전극재료, MEMS/NEMS 소자 및 바이오 소 자 등 다양한 분야로의 응용이 가능하다[1-5].

$\mathrm{UNCD}$ 박막의 응용성에 가장 직접적인 영향을 미치는 핵심 요소는 평탄한 표면특성 확보 여부이며, $\mathrm{UNCD}$ 박 막의 표면조도는 나노다이아몬드 핵생성을 위한 기판 표 면 전처리 및 seeding 공정 과정에서 결정된다[6-8]. 즉, 비 다이아몬드 기판 상에 낮은 표면조도를 갖는 평탄한 $\mathrm{UNCD}$ 박막을 증착하기 위해서는 $5 \mathrm{~nm}$ 이하의 매우 미 세한 크기를 갖는 나노다이아몬드 seed 입자들을 기판 표면에 높은 밀도로 균일하게 분포하도록 하는 것이 필 수적이다. 일반적으로, UNCD 박막 증착을 위한 seeding 
은 나노다이아몬드 seed 입자들을 DI water, 에탄올 또는 메탄올 등의 용매에 분산시킨 콜로이드 용액에 기판을 침 지하여 진행하며, 이때 사용되는 나노다이아몬드 seed 입 자로는 폭발법(detonation method) 으로 합성된 나노다이 아몬드 분말을 사용한다 $[9,10]$. 나노다이아몬드 분말을 구성하는 각각의 core 입자들은 $3 \sim 5 \mathrm{~nm}$ 범위의 매우 작은 크기를 가지지만, 폭발 후 냉각과정에서 core 입자들은 수백 나노미터에서 수 마이크로미터 범위의 거대한 크기 를 갖는 응집체를 형성하게 된다. 형성된 나노다이아몬드 응집체는 단순한 Van der Waals 결합 뿐만 아니라 공유 결합을 포함한 견고한 화학 결합으로도 연결되어 있어 종래의 초음파 처리법으로는 분산시키기가 매우 힘들다 $[11,12]$. 따라서, 낮은 표면 조도와 평탄한 표면 특성을 가지는 UNCD 박막을 증착하기 위해서는 seeding 공정 에 사용되는 나노다이아몬드 seed 입자들의 응집현상을 제어할 수 있는 기술을 개발하는 것이 매우 중요하다.

최근에 나노다이아몬드 입자들의 응집현상을 제어하기 위한 집중적인 연구가 진행되었고, 기계적 분쇄 또는 화 학적 표면 개질(surface chemical modification)을 통하 여 나노다이아몬드 입자의 응집성을 제어하는 것이 가능 하다는 결과들이 보고되었다. 기계적인 분쇄법으로는 미 세한 크기의 지르코니아 비드(zirconia bead)를 이용한 비드밀 분쇄과정 중에 강한 교반 또는 초음파로 전단력 (shear force)을 도입하는 방법이 나노다이아몬드 입자 응집을 완화시킬 수 있음이 보고되었다 $[13,14]$. 또한, 나노다이아몬드 입자 표면의 불소화 처리, $\mathrm{CH}_{4} / \mathrm{O}_{2}$ 플라 즈마 또는 수소 플라즈마 처리 등의 화학적 표면 개질 기술들을 통해서도 나노다이아몬드 입자의 분산 특성이 향상될 수 있다고 보고되었다[15-17]. 본 연구에서는 폭 발법으로 제조된 나노다이아몬드 seed 입자들을 산화 및 수소 분위기 하에서 열처리 하는 방법을 통하여 나노다 이아몬드 입자의 화학적 표면 개질을 시도하였다. 열처리 후 나노다이아몬드 입자 표면의 화학적 작용기(chemical functionalities) 변화를 확인하였고, 응집체의 크기가 현 저히 감소하였음을 확인하였다. 또한, 개질된 seed 입자 들을 사용한 seeding 공정 이후 $~ 10^{11} \mathrm{~cm}^{-2}$ 의 매우 높은 핵생성 밀도를 확보하였다.

\section{2. 실험과정}

본 연구에서는 폭발법으로 제조된 나노다이아몬드 분 말(Nanostructured \& Amorphous Materials Inc.)을 사 용하였다. 화학적 표면 개질을 위해 나노 다이아몬드 분 말을 산화 및 수소 분위기 하에서 $400 ~ 1000^{\circ} \mathrm{C}$ 온도 영 역에서 5 시간 동안 열처리를 하였다. 열처리 하지 않은 분말과 열처리된 분말을 DI water에 분산하여 30 분 동
안 초음파 처리를 한 다음 $5000 \mathrm{rpm}$ 의 회전 속도로 30 분 동안 원심분리를 진행하여 수용액 콜로이드를 준비하 였다. 준비된 수용액 콜로이드 시편들의 dynamic light scattering(DLS) 분석을 통해 표면 개질 처리 전, 후 입 자크기와 제타 전위를 비교하였다. 열처리 전, 후의 나노 다이아몬드 분말을 $\mathrm{KBr}$ 분말과 혼합하여 pellet 형태로 제작하였고, Fourier transformed infra-red spectroscopy (FT-IR) 흡수 모드 분석으로 표면 작용기 변화 여부를 확인하였다. Seeding 공정은 열처리 전, 후의 나노다이 아몬드 분말을 에탄올에 분산한 콜로이드 용액에 $2.5 \times$ $2.5 \mathrm{~cm}^{2}$ 크기의 $\mathrm{p}$-형 (100) $\mathrm{Si}$ 기판을 침지한 후 30 분 동안 초음파 처리를 통해 진행하였고, seeding된 기판 표면의 FE-SEM(Hitachi S4700) 관찰로 화학적 표면 개 질에 따른 핵생성 밀도 변화를 조사하였다.

\section{3. 결과 및 고찰}

Fig. 1에 열처리 전, 산화 및 수소분위기에서 열처리 한 나노다이아몬드 입자의 수용액 콜로이드 시편들의 DLS 제타 전위 측정 결과를 나타내었다. 열처리를 하지 않은 나노다이아몬드 분말의 경우 약 $-10 \mathrm{mV}$ 의 제타 전 위를 나타내었는데 이는 나노다이아몬드 표면에 존재하 는 산소를 함유한 작용기에 기인한 것으로서 상업적으로 판매되는 나노다이아몬드 분말들에서 전형적으로 관찰되 는 결과이다[18]. $400^{\circ} \mathrm{C}$, 산화 분위기에서 열처리된 시편 은 열처리 전에 비해 음의 방향으로 증가된 $-44.5 \mathrm{mV}$ 의 제타 전위를 나타내었다. $500^{\circ} \mathrm{C}$ 이상의 온도 영역의 산 화 분위기에서 열처리하였을 때에는 나노다이아몬드 입 자들이 $\mathrm{CO}$ 또는 $\mathrm{CO}_{2}$ 가스로 열산화 되는 반응이 활성 화됨에 따라 분말이 소실되는 현상이 관찰되어 더 이상 의 실험진행이 불가능하였다. 반면에, 수소 열처리한 나

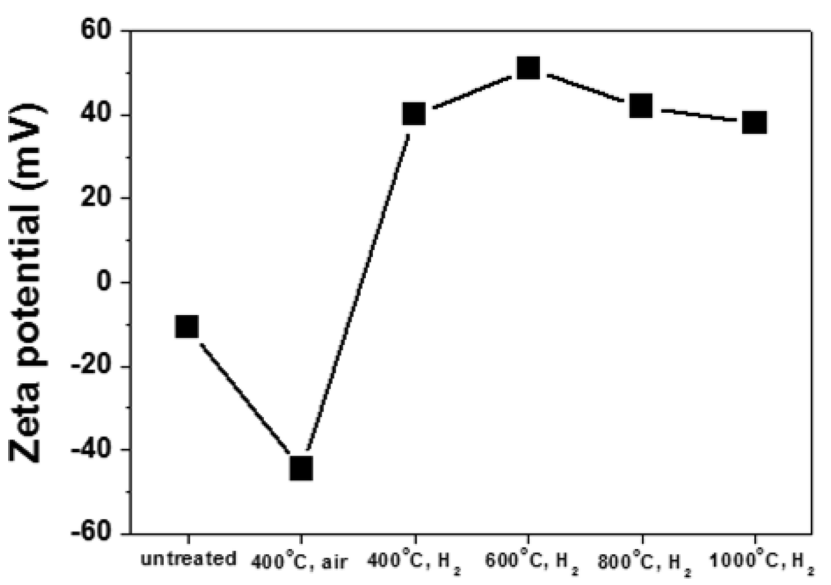

Fig. 1. Zeta potential of untreated, air and hydrogen heat-treated nanodiamond powders. 

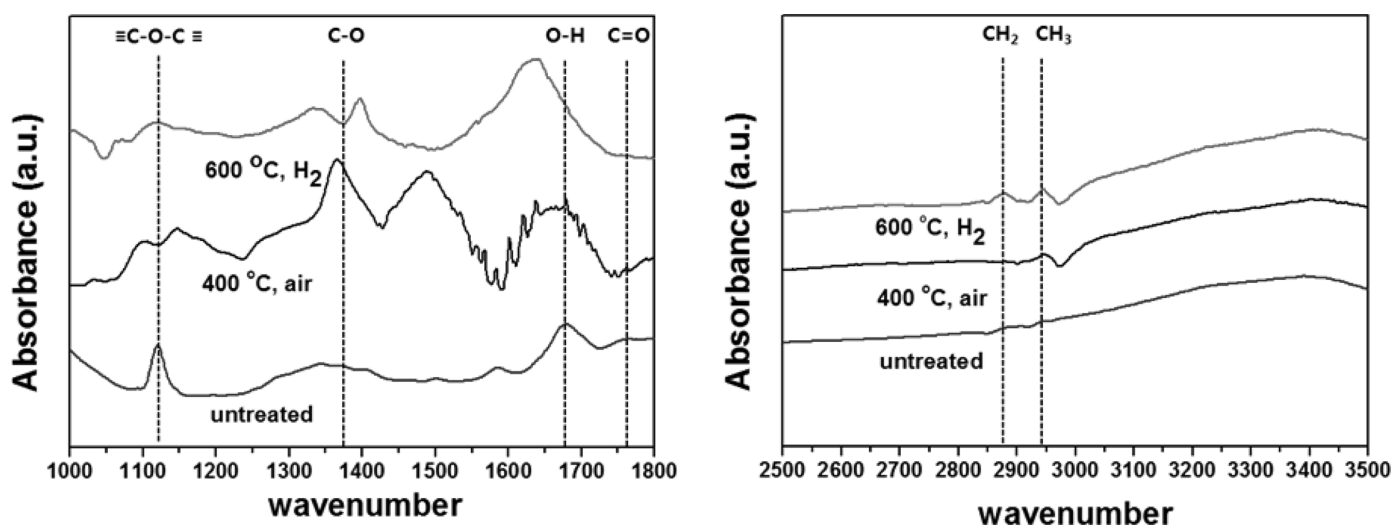

Fig. 2. FT-IR spectra of untreated, air and hydrogen heat-treated nanodiamond powders.

노다이아몬드 분말들로부터는 열처리 온도와 상관없이 양의 제타 전위값들이 측정되었는데, 이는 나노다이아몬 드 입자 내 전자와 DI water에 존재하는 hydronium 이 온 $\left(\mathrm{H}_{3} \mathrm{O}^{+}\right)$간의 상호작용 때문인 것으로 보인다[19, 20]. $600^{\circ} \mathrm{C}$, 수소 분위기에서 열처리된 나노다이아몬드 분말 로부터 $+50 \mathrm{mV}$ 의 가장 높은 제타 전위가 측정되었다. 일반적으로 절대값 $30 \mathrm{mV}$ 이상의 제타 전위 영역은 분 말 입자가 용매 내에서 응집 보다는 분산되는 특성을 나 타내는 안정화 영역으로 분류된다. 따라서 Fig. 1에 제 시한 제타 전위 측정 결과로부터 $400^{\circ} \mathrm{C}$, 산화 분위기 및 수소 열처리에 의해 나노다이아몬드 입자의 분산성이
향상되었음을 알 수 있다.

산화 및 수소 분위기에서의 열처리 전, 후 나노다이아 몬드 분말의 FT-IR 분석결과를 Fig. 2에 제시하였다. 열 처리 하지 않은 나노다이아몬드 분말에서는 epoxy 또는 ether 결합 형태의 탄소-산소 결합기와 수산기 $(\mathrm{O}-\mathrm{H})$ 가 각각 $\sim 1120 \mathrm{~cm}^{-1}, \sim 1660 \mathrm{~cm}^{-1}$ 에서 검출되었다. $400^{\circ} \mathrm{C}$, 산화 분위기에서 열처리한 분말의 경우 카르복실산기 (carboxyl acid) 탄소-산소 결합기 $(\mathrm{C}-\mathrm{O}, \mathrm{C}=\mathrm{O})$ 에 해당하 는 peak들이 $\sim 1350 \mathrm{~cm}^{-1}$ 및 $1780 \mathrm{~cm}^{-1}$ 영역에서 관찰되 었는데, 이 결과는 나노다이아몬드 입자 표면의 산화가 진행됨에 따라 탄소-산소 간 표면 작용기가 변화하였음
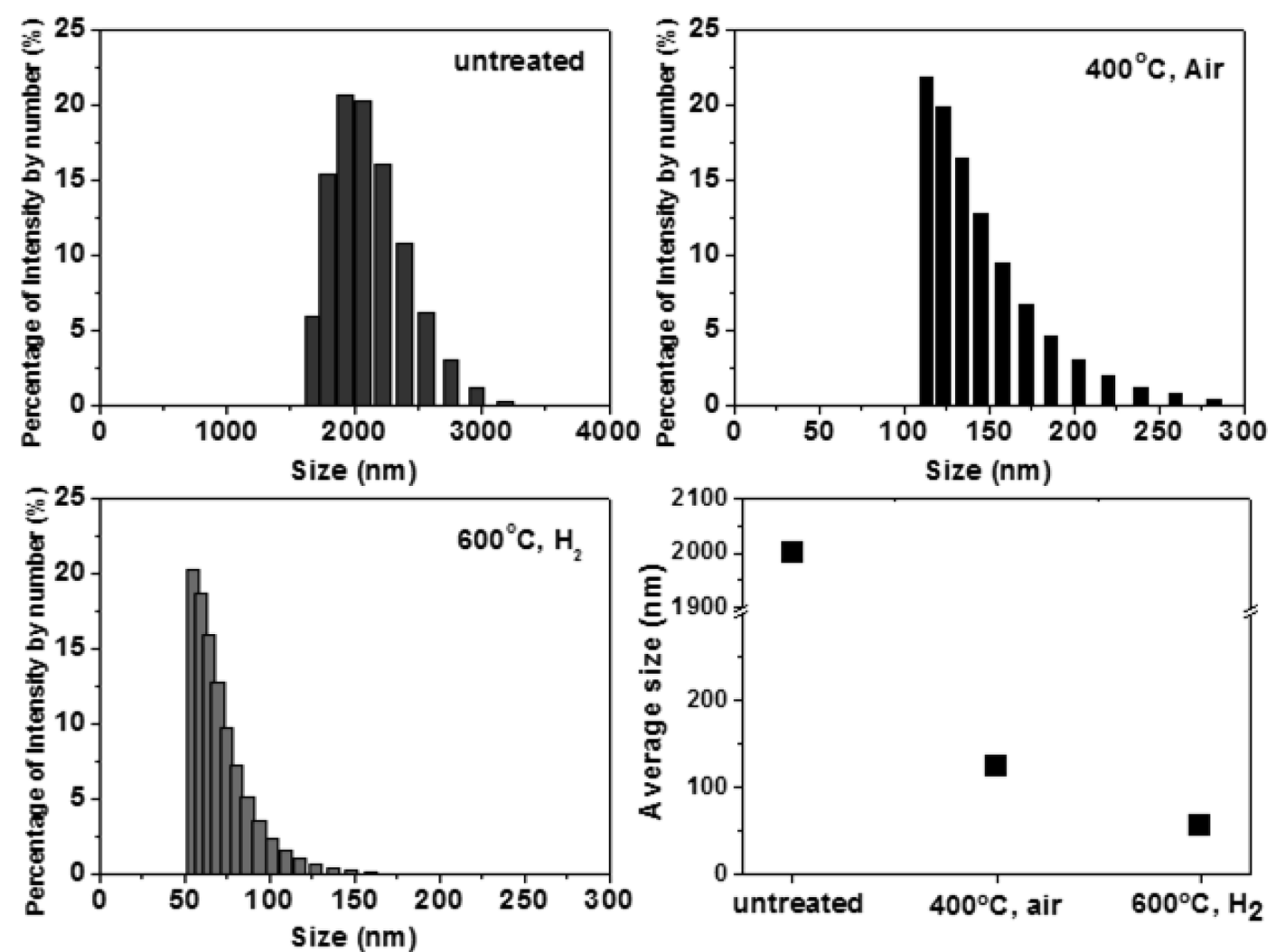

Fig. 3. DLS size distribution and average particle size of untreated, air and hydrogen heat-treated nanodiamond powders. 
을 보여주고 있다. 수소 열처리 후에는 탄소-산소 간 결 합기 peak 강도가 현저하게 감소한 반면에 탄소-수소 결 합기 peak 들이 2870 2950 $\mathrm{cm}^{-1}$ 에서 나타났다. 이로부 터 수소 열처리에 의해 나노다이아몬드 입자 표면이 수 소화되는 화학적 개질이 진행되었음을 확인하였다.

Fig. 3은 열처리 전과 산화 및 수소분위기에서 열처리 한 나노다이아몬드 분말의 크기에 대한 DLS 분석결과 를 보여주고 있다. 열처리 전의 나노다이아몬드 분말의 평균 입자 크기는 약 $2 \mu \mathrm{m}$ 으로 core 입자들이 강하게 응집되어 있음을 보여주고 있다. 이는 제타 전위 측정으 로부터 예측된 경향과 일치하는 결과이다. 산화 및 수소 분위기에서의 열처리를 통한 화학적 표면 개질 이후 나 노다이아몬드 응집체의 크기는 크게 감소하였으며, 특히, 가장 높은 양의 제타 전위를 나타낸 $600^{\circ} \mathrm{C}$, 수소 분위 기에서 열처리된 나노다이아몬드 분말의 경우 약 $55 \mathrm{~nm}$ 의 평균 크기를 나타내었다. DLS 측정 결과로부터 산화 및 수소 열처리를 통하여 나노다이아몬드 입자들의 응집 제어가 가능하다는 것을 확인하였다.

Fig. 4에 열처리 전과 산화 및 수소 분위기에서 열처 리 후의 나노 다이아몬드 입자들을 초음파 처리법으로 에탄올에 분산시킨 콜로이드 중에서 seeding한 $\mathrm{Si}$ 기판 표면들의 SEM 이미지를 비교하였다. 열처리하지 않은 나노다이아몬드 seed 입자의 경우, 강한 응집성으로 인
해 $\mathrm{Si}$ 기판 표면에 seeding된 입자들의 크기가 상대적으 로 크고, 핵형성 밀도도 $~ 5.8 \times 10^{9} \mathrm{~cm}^{-2}$ 으로 가장 낮은 값을 나타내었다. 이와는 대조적으로 $600^{\circ} \mathrm{C}$, 수소 분위 기에서 열처리 한 나노다이아몬드 seed 입자들은 $\mathrm{Si}$ 기 판 표면에 20 30 nm 정도의 더 작은 크기를 갖는 응집 체로 균일하게 분포하고 있음을 알 수 있다. 또한, 열처 리 하지 않은 seed 입자들에 비해 약 50배 정도 크게 향상된 $~ 2.7 \times 10^{11} \mathrm{~cm}^{-2}$ 의 매우 높은 핵형성 밀도를 나 타내었다. 핵형성 밀도 향상은 산화 열처리된 seed 입자 의 경우에도 역시 관찰되었다. 이러한 결과로부터 산화 및 수소 분위기에서의 열처리를 통한 화학적 표면 개질 이 UNCD 박막 증착을 위한 나노다이아몬드 핵형성 밀 도를 크게 향상시키는 효과를 나타냄을 확인하였다.

\section{4. 결 론}

$\mathrm{UNCD}$ 박막 증착을 위한 seeding 공정에 사용되는 나 노다이아몬드 seed 입자들의 산화 및 수소 열처리를 통 한 화학적 표면 개질이 seed 입자들의 응집성 완화와 핵 형성 밀도 향상에 미치는 영향에 대하여 조사하였다. 산 화 및 수소 열처리 후 제타 전위가 증가하고 표면 작용 기가 변화됨에 따라 나노다이아몬드 응집체의 크기가 크
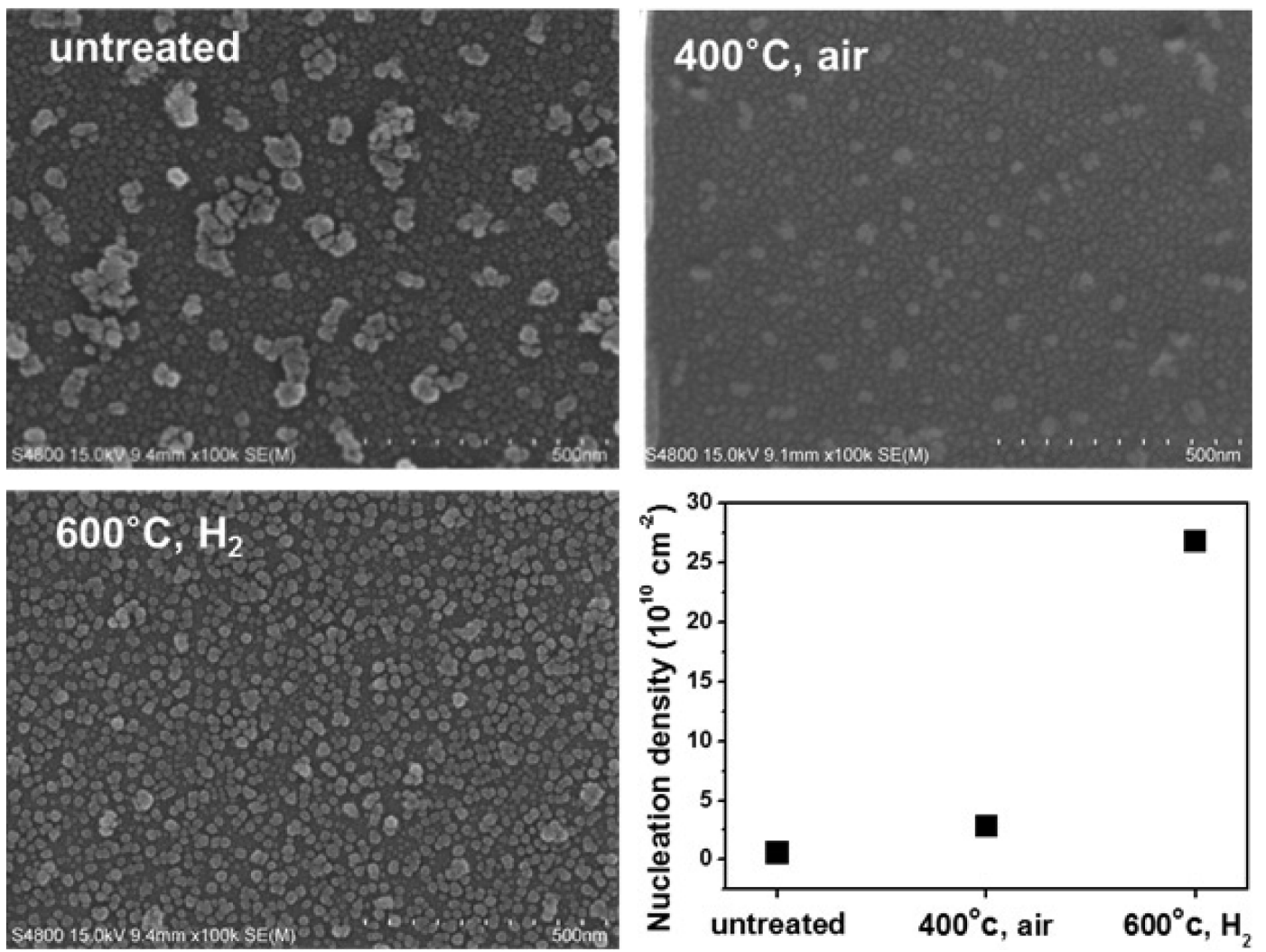

Fig. 4. SEM micrographs and nucleation density of Si substrates after seeding with untreated, air and hydrogen heat-treated nanodiamond particles. 
게 감소함을 확인하였다. 특히, $600^{\circ} \mathrm{C}$, 수소 열처리 이 후 입자 표면의 수소화에 의해 $+50 \mathrm{mV}$ 이상의 가장 높 은 제타 전위와 현저히 작아진 $~ 55 \mathrm{~nm}$ 응집체 평균 크 기가 측정되었고, $\mathrm{Si}$ 기판 상에서 $2.7 \times 10^{11} \mathrm{~cm}^{-2}$ 의 매 우 높은 핵형성 밀도를 확보하였다. 본 연구를 통하여 산화 및 수소 열처리를 통한 화학적 표면 개질이 나노다 이아몬드 seed 입자들의 응집성을 완화시키고 현저한 입 자크기 감소를 유도하며, 더 나아가 핵형성 밀도를 크게 향상시키는 효과를 나타냄을 확인하였다.

\section{감사의 글}

이 논문은 2012년도 정부(교육과학기술부)의 재원으로 한국연구재단의 지원을 받아 수행된 연구임(원자력연구기 반확충사업 전략기초연구, No. 2012M2B2A9A02030016).

\section{참 고 문 헌}

[1] J. Hees, N. Heidrich, W. Pletschen, R.E. Sah, M. Wolfer, O.A. Williams, V. Lebedev, C.E. Nebel and O. Ambacher, "Piezoelectric actuated micro-resonators based on the growth of diamond on aluminum nitride thin films", Nanotechnology 24 (2013) 025601.

[2] N. Moldovan, O. Auciello, A.V. Sumant, J.A. Carlisle, R. Divan, D.M. Gruen, A.R. Krauss, D.C. Mancini, A. Jayatissa and J. Tucek, "Micromachining of ultrananocrystalline diamond", Proc. SPIE. 4557 (2001) 288.

[ 3 ] M.W. Geis, N.N. Efremow, K.E. Krohn, J.C. Twichell, T.M. Lyszczarz, R. Kalish, J.A. Greer and M.D. Tabat, "A new surface electron-emission mechanism in diamond cathode", Nature 393 (1998) 431.

[ 4 ] J. Cvacka, V. Quaiserova, J.W. Park, Y. Show, A. Muck, Jr. and G.M. Swain, "Boron-doped diamond microelectrodes for use in capillary electrophoresis with electrochemical detection", Anal. Chem. 75 (2003) 2678.

[ 5 ] O. Auciello, A.V. Sumant, "Status review of the science and technology of ultrananocrystalline diamond (UNCD) films and application to multifunctional devices", Diamond Relat. Mater. 19 (2010) 699.

[6] O.A. Williams, "Nanocrystalline diamond", Diamond Relat. Mater. 20 (2011) 621.
[ 7 ] J.C. Park, O.G. Jeong, S.Y. Kim, S.J. Park, Y-.H. Yun and Hyun Cho, "Silicon surface texturing for enhanced nanocrystalline diamond seeding efficiency", J. Korean Cryst. Growth Cryst. Technol. 23 (2013) 86.

[ 8 ] T.G. Kim, Y.H. Shin, H. Cho and J.K. Kim, "Synthesis of transparent diamond-like carbon film on the glass by radio-frequency plasma enhanced chemical vapor deposition", J. Korean Cryst. Growth Cryst. Technol. 22 (2012) 190.

[ 9] V.Y. Dolmatov, "Detonation synthesis ultradispersed diamonds properties and applications", Russ. Chem. Rev. 70 (2008) 607.

[10] K.V. Volkov, V.V. Danilenko and V.I. Elin, "Synthesis of diamond from the carbon in the detonation products of explosives", Fiz. Goreniya Vzryva 26 (1990) 123.

[11] E. Osawa, in: A.V.D. Gruen, O. Shenderova (eds.), Synthesis, Properties and Applications of Ultrananocrystalline Diamond p. 231-240 (Springer, 2005).

[12] A. Krueger, "The structure and reactivity of nanoscale diamond", J. Mater. Chem. 18 (2008) 1485.

[13] M. Ozawa, M. Inaguma, M. Takahashi, F. Kataoka, K. Krueger and E. Osawa, "Preparation and behavior of brownish, clear nanodiamond colloids", Adv. Mater. 19 (2007) 1201.

[14] A. Krueger, M. Ozawa, G. Jarre, Y. Liang, J. Stegk and L. Lu, "Deagglomeration and functionalisation of detonation diamond", Phys. Status Solidi A 204 (2007) 2881.

[15] Y. Liu, Z. Gu, J.L. Margrave and V.N. Khabashesku, "Functionalization of nanoscale diamond powder:fluoro-, alkyl-, amino-, and amino acid-nanodiamond derivatives", Chem. Mater. 16 (2004) 3924.

[16] Q. Yu, Y.J. Kim and H. Ma, "Plasma treatment of diamond nanoparticles for dispersion improvement in water", Appl. Phys. Lett. 88 (2006) 231503.

[17] J.C. Arnault, T. Petit, H. Girard, A. Chavanne, C. Gesset, M. Sennour and M. Chaigneau, "Surface chemical modifications and surface reactivity of nanodiamonds hydrogenated by CVD plasma", Phys. Chem. Chem. Phys. 13 (2011) 11481.

[18] H.P. Boehm, "Surface oxides on carbon and their analysis: a critical assessment", Carbon 40 (2002) 145.

[19] O.A. Williams, J. Hees, C. Dieker, W. Jager, L. Kirste and C.E. Nebel, "Size-dependent reactivity of diamond nanoparticles", ACS Nano 4 (2010) 4824.

[20] C. Leon, J.M. Solar, V. Calemma and L.R. Radovic, "Evidence for the protonation of basal plane sites on carbon", Carbon 30 (1992) 797. 